\title{
A Highly Sensitive Ammonia Gas Sensor Using Micrometer-Sized Core-Shell-Type Spherical Polyaniline Particles
}

\author{
Masanobu Matsuguchi *(D), Tomoki Nakamae, Ryoya Fujisada and Shunsuke Shiba \\ Department of Materials Science and Biotechnology, Graduate School of Science and Engineering, \\ Ehime University, Bunkyo-cho 3, Ehime, Matsuyama 790-8577, Japan; xsbry422@outlook.jp (T.N.); \\ i844027m@mails.cc.ehime-u.ac.jp (R.F.); shiba.shunsuke.yu@ehime-u.ac.jp (S.S.) \\ * Correspondence: matsuguchi.masanobu.mm@ehime-u.ac.jp; Tel.: +81-89-927-9933
}

check for updates

Citation: Matsuguchi, M.; Nakamae,

T.; Fujisada, R.; Shiba, S. A Highly

Sensitive Ammonia Gas Sensor Using Micrometer-Sized Core-Shell-Type Spherical Polyaniline Particles. Sensors 2021, 21, 7522. https:// doi.org/10.3390/s21227522

Academic Editor: Tamara Basova

Received: 25 October 2021

Accepted: 10 November 2021

Published: 12 November 2021

Publisher's Note: MDPI stays neutral with regard to jurisdictional claims in published maps and institutional affiliations.

Copyright: (c) 2021 by the authors. Licensee MDPI, Basel, Switzerland. This article is an open access article distributed under the terms and conditions of the Creative Commons Attribution (CC BY) license (https:// creativecommons.org/licenses/by/ $4.0 /)$.

\begin{abstract}
A highly sensitive $\mathrm{NH}_{3}$ gas sensor based on micrometer-sized polyaniline (PANI) spheres was successfully fabricated. The PANI microspheres were prepared via a facile in situ chemical oxidation polymerization in a polystyrene microsphere dispersion solution, resulting in a coreshell structure. The sensor response increased as the diameter of the microspheres increased. The PSt@PANI(4.5) sensor, which had microspheres with a $4.5 \mu \mathrm{m}$ average diameter, showed the largest response value of 77 for 100 ppm dry $\mathrm{NH}_{3}$ gas at $30{ }^{\circ} \mathrm{C}$, which was 20 times that of the PANIdeposited film-based sensor. Even considering measurement error, the calculated detection limit was $46 \mathrm{ppb}$. A possible reason for why high sensitivity was achieved is simply the use of micrometer-sized PANI spherical particles. This research succeeded in providing a new and simple technology for developing a high-sensitivity $\mathrm{NH}_{3}$ gas sensor that operates at room temperature.
\end{abstract}

Keywords: polyaniline; $\mathrm{NH}_{3}$ gas sensor; microspheres; core-shell structure

\section{Introduction}

Ammonia $\left(\mathrm{NH}_{3}\right)$ gas is not only a common air pollutant but is also expected to be an important energy source in the coming hydrogen society [1,2]. In line with this societal trend, environmentally friendly, low-cost methods for producing ammonia have been studied $[3,4]$. In application areas such as manufacturing plants and transportation processes, ammonia gas needs to be monitored for leaks because of its toxicity and adverse effects on the environment [5]. Moreover, $\mathrm{NH}_{3}$ gas is known as a medical biomarker for kidney disorders and Helicobacter pylori bacteria-induced stomach infections [5,6]. Therefore, ppb-level $\mathrm{NH}_{3}$ gas is of great significance for medical diagnostics.

In light of this background, there has been a demand for $\mathrm{NH}_{3}$ gas sensors that are not only highly sensitive, but also simple, low-cost, and non-heatable. Polyaniline (PANI) has the potential to realize such requirements $[7,8]$ and has long been studied as a $\mathrm{NH}_{3}$ gas sensing material due to its easy synthesis, unique doping/dedoping processes, and good environmental stability. Moreover, PANI displays stable electrical conduction at room temperature, which is advantageous for reducing the power consumption of the sensor and for increasing portability. PANI can be synthesized easily by chemical oxidative polymerization of aniline hydrochloride [9]. However, the sensing characteristics of a sensor prepared by drop-coating an insoluble PANI dispersion solution on a sensor substrate were insufficient for practical use. This is because the formed film had a granular structure consisting of aggregated polyaniline chains, resulting in a dense film with poor gas diffusivity. The formation of thin films is expected to decrease the diffusion distance of gas molecules, resulting in a shorter response time. In general, however, reducing the film thickness also reduces the magnitude of the sensor response.

There are two main research approaches to realize the detection of $\mathrm{NH}_{3}$ gas at the ppb level. The first approach is a preparation of PANI nanocomposite materials. Various 
composites of PANI with carbon nanotubes or graphene [10-14], metal oxide semiconductors [15-17], and polymer fibers [18-20] have been reported to be effective for enhancing sensitivity. As an alternative approach, it has been widely reported that developing structure-controlled PANI films with large surface areas and good gas diffusivity, such as nanofibers [21-25], nanorods [26], and nanotubes [27], is an effective way to improve gas sensing properties.

The key idea of the present study is to use micrometer-sized PANI spherical particles for the sensing film. Films consisting of spherical particles of uniform size are expected to have high gas diffusivity because of the large amount of space inside the film. Moreover, the net volume of the space between spherical particles is expected to increase as the size of the spheres increases. Therefore, we came up with the idea of producing micrometer-sized PANI spherical particles. The benefit of this approach is that it leads to the enhancement of the interaction between PANI chains and gas molecules, resulting in the achievement of ppb-level gas detection. However, it is hard to produce spherical particles of uniform size only with PANI. Wallace et al. reported that polyaniline nanoparticles were synthesized by emulsion polymerization inside dodecylbenzenesulfonic acid (DBSA) micelles [28]. However, the nanoparticles were not perfect spheres, and they were several tens of nanometers in diameter. If particles are neither spherical nor small, the density of the formed film will increase, and improvement of gas diffusivity cannot be expected. An alternative way to reliably obtain PANI spherical particles is to coat conventional spherical polymers with PANI. Many so-called core-shell types of conducting polymers have been reported to improve processability and to coat particles [29-33]. Among these spherical particles, we have chosen PANI-coated PS microspheres because polystyrene microspheres can be easily prepared via a free-radical-initiated polymerization method such as dispersion polymerization. Moreover, by optimizing the polymerization conditions, the particle size can be tuned within a wide diameter range [34,35]. PANI-coated PS spheres have been subjected to electrochemical measurements [36,37], but few examples of applications to gas sensors have been reported so far. Li et al. prepared PANI nanoparticles, each composed of a PANI shell and a sulfonated PSt core, and extracted the core to make them hollow [38]. The hollow nanoparticles had a rambutan-like structure, and the hollow part was $250 \mathrm{~nm}$, with a nanorod length of $100 \mathrm{~nm}$. The $\mathrm{NH}_{3}$ gas sensing characteristics of the hollow nanoparticles at room temperature included high response values and fast response/recovery times.

In this paper, we report the results of a further improvement in sensitivity by preparing micrometer-order PANI spherical particles and investigating the effect of particle size on the $\mathrm{NH}_{3}$ gas sensing response.

\section{Materials and Methods}

\subsection{Materials}

The following reagents were used for the synthesis of polystyrene microspheres. Styrene as a monomer, methanol and ethanol as solvents, and polyvinylpyrrolidone as a dispersion stabilizer were obtained from Fujifilm Wako Pure Chemical. Azobisisobutyronitrile as a polymerization initiator was obtained from Sigma-Aldrich Japan. For the polymerization of polyaniline, aniline hydrochloride monomer and ammonium persulfate as an oxidant were obtained from Fujifilm Wako Pure Chemical. The styrene monomer was distilled under reduced pressure before polymerization to remove the polymerization inhibitor. Other reagents were of analytical grade or better and were used as received.

\subsection{Preparation of Polystyrene Microspheres}

A dispersion polymerization was performed to prepare micrometer-sized polystyrene spherical particles. The size of polystyrene microspheres can be controlled by the concentration of the dispersion stabilizer, the reaction solvent, the volume of the reaction vessel, and the polymerization temperature $[34,35]$. In this study, four sizes of microspheres were prepared. Each is hereafter referred to as Samples 1-4, respectively. 
As an example of a synthesis procedure, the preparation of Sample 2 is described here. First, a $90 \mathrm{~mL}$ ethanol solution containing $2.5 \mathrm{w} / \mathrm{v} \%$ polyvinylpyrrolidone (PVP) was placed in a three-necked $300 \mathrm{~mL}$ flask, and the mixture was stirred at $70{ }^{\circ} \mathrm{C}$ for $3 \mathrm{~h}$ under a nitrogen atmosphere. Then, $15 \mathrm{~g}$ of styrene (St), in which $0.33 \mathrm{~g}$ of azobisisobutyronitrile was dissolved, was added dropwise to the three-necked flask, and the mixture was stirred for $24 \mathrm{~h}$. The obtained milky-white latex was centrifuged to remove the supernatant containing the unreacted materials. The precipitate was redispersed in ethanol and centrifuged again. These procedures were repeated three times to finally obtain purified PSt microspheres.

\subsection{Preparation of the Core-Shell Type of Polyaniline Microspheres}

Chemical oxidation polymerization of aniline was performed in a suspension of aqueous solution of PSt microspheres having different sizes, and then the surface of the PSt core was coated with polyaniline [36]. Microspheres with a structure consisting of a PSt core and a PANI shell are referred to as PSt@PANI( $x$ ) hereafter. Here, " $x$ " represents the average diameter of PANI-coated PSt microspheres in $\mu \mathrm{m}$. To make the thickness of the PANI shells of all microspheres uniform, the concentration of the suspension of PSt microspheres was adjusted so that the total surface area of PSt microspheres in the solution was identical.

A typical preparation procedure of PSt@PANI(2.5) using the Sample 2 microspheres was as follows. First, $100 \mathrm{~mL}$ of a suspension of $1.6 \mathrm{wt} \%$ PSt microspheres was prepared. Next, $1.11 \mathrm{~g}$ of aniline hydrochloride was added to the solution and cooled in an ice bath at $0{ }^{\circ} \mathrm{C}$ for $2 \mathrm{~h}$. Ammonium persulfate was then added, and polymerization was performed at $0{ }^{\circ} \mathrm{C}$ for $5 \mathrm{~h}$ and further at room temperature for $24 \mathrm{~h}$. The obtained dispersion solution of PANI-coated microspheres was centrifuged to remove the supernatant, followed by dispersion in distilled water, and then centrifuged again. This centrifugation procedure was repeated until the supernatant became colorless and transparent. The obtained microspheres coated with $\mathrm{HCl}$-doped PANI were dispersed in $25 \%$ aqueous ammonia and stirred for $24 \mathrm{~h}$ for the de-doping of $\mathrm{HCl}$. Then, the microspheres were dispersed in $0.025 \mathrm{M}$ of sulfuric acid, stirred for $24 \mathrm{~h}$ for doping again, and finally microspheres coated with $\mathrm{H}_{2} \mathrm{SO}_{4}$-doped PANI were obtained.

\subsection{Preparation of Sensing Films}

The dispersion aqueous solution of $\mathrm{H}_{2} \mathrm{SO}_{4}$-doped PANI microspheres was drop-coated onto an alumina substrate having a pair of interdigitated gold electrodes with an electrode spacing of $200 \mu \mathrm{m}$ (Figure S1). The film was heat-treated at $150{ }^{\circ} \mathrm{C}$ for $20 \mathrm{~min}$ in air.

\subsection{Measurement of $\mathrm{NH}_{3}$ Gas Sensing Properties}

All sensors were set in a home-made thermostated measuring cell. The experimental setup is shown in Figure S2. Measurement was performed at $30^{\circ} \mathrm{C}$ in flows of different concentrations of $\mathrm{NH}_{3}$ gas diluted with $\mathrm{N}_{2}$. The variation in the electrical resistance was measured with an electrometer $(8252, \mathrm{ADC})$. Baseline measurements $\left(R_{0}\right)$ were performed in nitrogen, followed by measurement of the resistance of the sensor in $\mathrm{NH}_{3}\left(R_{\mathrm{g}}\right)$ in various concentrations. The magnitude of the sensor response was defined as

$$
S=R_{\mathrm{g}} / R_{0} .
$$

Response ( $\left.T_{\text {res }}\right)$ and recovery time ( $\left.T_{\text {rec }}\right)$ were each defined as the time required to reach $90 \%$ of the total resistance change.

\subsection{Characterization}

The morphologies of the PSt microspheres before and after PANI coating were observed using a field emission scanning electron microscope (FE-SEM) (S-5500, Hitachi High-Technologies). The X-ray diffraction (XRD) analysis was carried out on an X'pert Pro (PANalytical) with $\mathrm{Cu}$ Ka radiation. 


\section{Results and Discussion}

\subsection{Characterization of the Core-Shell Type of Polyaniline Microspheres}

Figure 1a-d shows SEM images of the PSt of Samples 1 to 4 before PANI coating. All PSt samples prepared were proved to be spherical. Their estimated diameters are summarized in Table 1, and all spheres were confirmed to be in the order of micrometers. The table also shows the coefficients of variation (CV). Since the CV values were small in all microspheres, it was confirmed that PSt microspheres with high monodispersity were obtained. SEM images of PSt microspheres after PANI coating are shown in Figure $1 a^{\prime}-d^{\prime}$. PANI homogeneously covered the surfaces of all the PSt microspheres. Coating the PSt microspheres slightly increased their diameters, and the thickness of the polyaniline shell was estimated from the difference in the microspheres' radii from before to after the PANI coating. As shown in Table 1, in all microspheres, the polyaniline shell layer was found to be about $200-250 \mathrm{~nm}$.
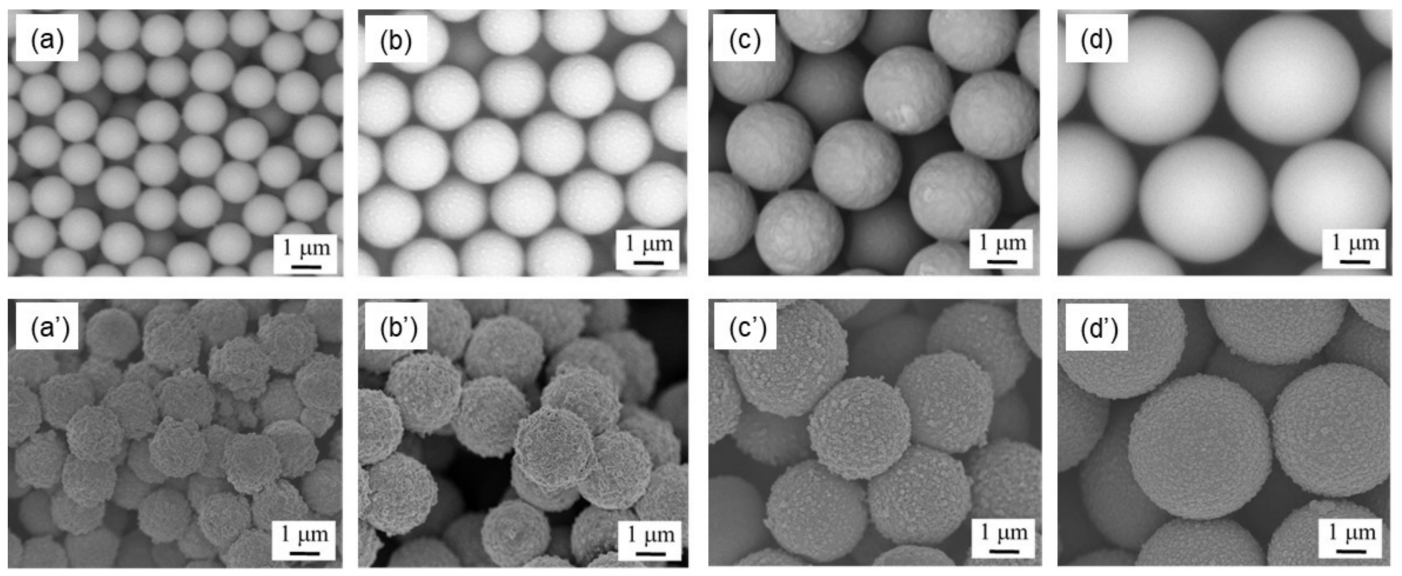

Figure 1. SEM images of PSt microspheres before and after PANI coating: (a, $\left.\mathbf{a}^{\prime}\right)$ Sample 1; (b, $\left.\mathbf{b}^{\prime}\right)$ Sample 2; (c, $\left.\mathbf{c}^{\prime}\right)$ Sample 3; and (d,d') Sample 4 .

Table 1. Average diameter (AD) and coefficient of variation (CV) of PSt- and PANI-coated PSt microspheres, and estimated thickness of PANI shell layer.

\begin{tabular}{cccccc}
\hline & \multicolumn{2}{c}{ PSt } & \multicolumn{2}{c}{ PANI-PSt } & \multirow{2}{*}{$\begin{array}{c}\text { Thickness of PANI } \\
\text { Shell Layer (nm) }\end{array}$} \\
\cline { 1 - 4 } Sample No. & AD $(\mu \mathrm{m})$ & CV (\%) & AD $(\mu \mathbf{m})$ & CV (\%) & 250 \\
\hline 1 & 1.4 & 3.4 & 1.9 & 6.3 & 250 \\
2 & 2.0 & 1.4 & 2.5 & 3.5 & 250 \\
3 & 3.1 & 7.2 & 3.6 & 10.7 & 200 \\
\hline
\end{tabular}

It is well known that the crystallinity of PANI has a significant effect on conductivity and gas sensor characteristics [39,40]. The crystal structure of PANI coated on a microsphere surface was confirmed by XRD measurement. The X-ray diffraction patterns obtained by PANI-coated microspheres with different particle sizes are shown in Figure 2. It was shown that each PANI microsphere had a broad diffraction peak of approximately equal intensity centered at $2 \theta=20^{\circ}$. However, the peak is also seen in PSt microspheres and is reported as a typical XRD feature of amorphous PSt [41]. Crystallized PANI is known to have a sharp peak at $2 \theta=25.6^{\circ}$, which is derived from the periodicity perpendicular to the PANI polymer chains $[42,43]$. The corresponding peak was seen in both PANI microspheres, indicating the semi-crystalline phase. However, the peak was very weak and broad, suggesting low crystallinity of PANI on the surface of each microsphere. This result is natural because the coating method and conditions were the same; only the core size was different. 


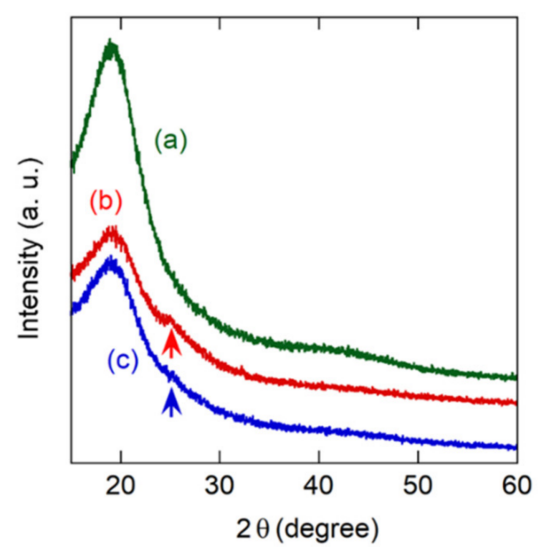

Figure 2. XRD patterns of (a) PSt(4.1) microspheres, (b) PSt@PANI(2.5) microspheres, and (c) PSt@PANI(4.5) microspheres.

\subsection{Sensing Properties toward $\mathrm{NH}_{3}$ Gas}

$\mathrm{NH}_{3}$ gas adsorption on the PANI-coated microspheres led to a large increase in electrical resistance. Then, after the sensor was exposed to dry $\mathrm{N}_{2}$, the resistance reverted toward the initial value. This reversible response of PANI to $\mathrm{NH}_{3}$ gas can be explained by a wellknown sensing mechanism: the process of protonation-deprotonation (Figure S3) [40].

A comparison of the magnitudes of the responses obtained for the PSt@PANI(x) sensors is shown in Figure 3a. For this purpose, sensors with similar sensor resistances of about $100 \mathrm{k} \Omega$ were selected. The polyaniline-deposited film (d.f.) formed by the conventional drop-cast method is also shown. As expected, the sensor using microspheres showed a greater sensor response than the sensor using the conventional drop-casting film. Among the microsphere-based sensors, PSt@PANI(4.5) showed the greatest sensor response, which was 20 times higher than that of the sensor based on deposited film. As shown in Figure 2, it is unlikely that the difference in the crystallinity of PANI had a significant effect on the sensor response with different microsphere sizes. Consequently, as will be explained later, this enhancement of the sensor response can be expected to be closely related to the size of the microspheres. In this study, PANI microspheres with a diameter larger than $4.5 \mathrm{~mm}$ were not examined because of the difficulty of preparing larger PSt microspheres.

Figure $3 \mathrm{~b}$ exhibits the transient response curves of each sensor when the $\mathrm{NH}_{3}$ gas concentration was reduced by $50 \mathrm{ppm}$ from 250 to $50 \mathrm{ppm}$. All sensors responded reversibly to ammonia gas, showing faster response and reversibility, especially at lower concentrations. However, the estimated response and recovery times at $50 \mathrm{ppm}$ were $T_{\text {res }}=700 \mathrm{~s}$ and $T_{\text {rec }}$ $=1050 \mathrm{~s}$, respectively, which were longer than those of the PANI-based sensors reported so far. The reason for this apparently slow response is that in our measuring setup, it takes a long time to replace the gas in the measuring cell, so that it is not possible to distinguish between the actual response time and the gas filling time. Therefore, the response/recovery times estimated in this study may be longer than the actual time.

The ammonia gas concentration dependence of the sensor response is shown in Figure 3c. Although the response of each sensor changed linearly within the measured $\mathrm{NH}_{3}$ gas concentration range, the sensitivity estimated from the slope of the straight line was the highest for the film consisting of PSt@PANI(4.5), which was 25 times that of the conventionally deposited film sensor. The response value for PSt@PANI(4.5) was $S=77$ toward $100 \mathrm{ppm} \mathrm{NH}_{3}$ at room temperature. Due to the very large sensitivity, the limit of detection was estimated using Equation (2) considering the standard deviation $\sigma$ of the base line, that the slope of the calibration curve was $46 \mathrm{ppb}$, and expecting that ammonia gas can be detected at the sub-ppm level.

$$
\mathrm{LOD}=3.3 \sigma / \text { slope }
$$


(a)

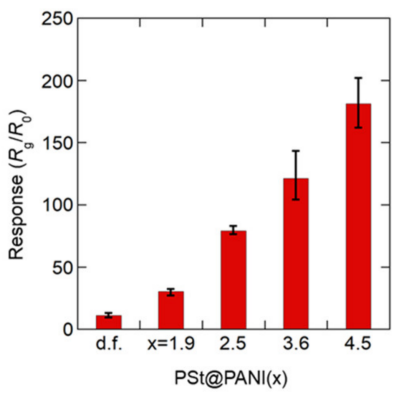

(c)

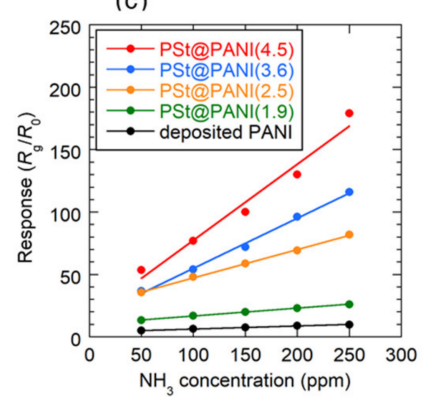

(b)

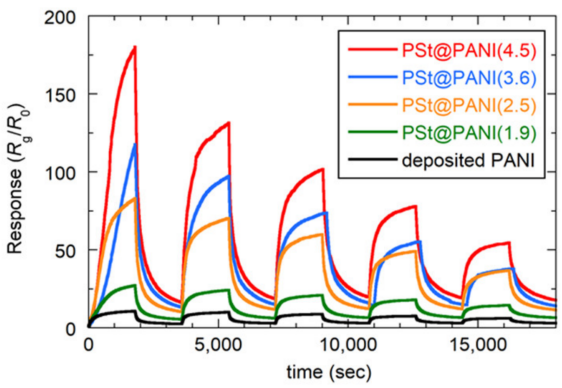

(d)

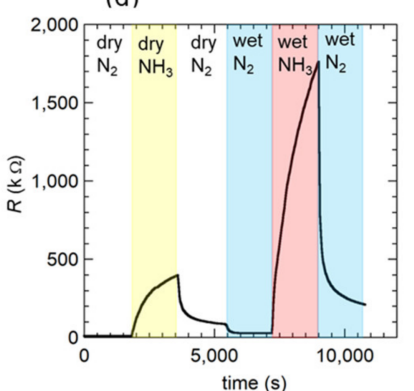

Figure 3. $\mathrm{NH}_{3}$ gas sensing characteristics obtained for the PSt@PANI(x) sensor: (a) magnitude of the sensor response toward $250 \mathrm{ppm}$ dry $\mathrm{NH}_{3}$, (b) transient response curves when the dry $\mathrm{NH}_{3}$ gas concentration is reduced by $50 \mathrm{ppm}$ from $250 \mathrm{ppm}$ to $50 \mathrm{ppm}$, (c) calibration curves between 50-250 ppm dry $\mathrm{NH}_{3}$ gas, and (d) effect of the humidity $(50 \% \mathrm{RH})$ on the sensor response of the PSt@PANI(1.9) sensor. All measurements were performed at $30^{\circ} \mathrm{C}$.

It is well known that humidity affects the electrical conductivity of PANI, and its application to a humidity sensor has been studied [44]. Therefore, atmospheric humidity also affects the characteristics of a PANI-based $\mathrm{NH}_{3}$ gas sensor [15,40,45]. Figure $3 \mathrm{~d}$ shows the results of an investigation into the effect of relative humidity (\%RH) on the response of the PSt@PANI(1.9) sensor. After the sensor response to $\mathrm{NH}_{3}$ gas was measured for one cycle in a dry atmosphere, switching from dry $\mathrm{N}_{2}$ to wet $\mathrm{N}_{2}(50 \% \mathrm{RH})$ reduced the electrical resistance. The cause of this resistance reduction has been explained as a "proton effect", that is, doping with protons generated by the dissociation of water molecules [11,44]. Subsequent exposure to $\mathrm{NH}_{3}$ gas humidified to $50 \% \mathrm{RH}$ significantly increased the resistance. The resulting response value was $S=62$, which was 1.7 times larger than that of $S=37$ in a dry atmosphere. Many groups have reported a complex mechanism underlying humidity's effect on the $\mathrm{NH}_{3}$ gas sensing of PANI. The increase in the response value can be explained by the "swelling effect" $[44,46]$ and/or the capture of protons from the acidified PANI by $\mathrm{OH}^{-}$generated through the following reaction [38]:

$$
\mathrm{NH}_{3}+\mathrm{H}_{2} \mathrm{O} \rightleftarrows \mathrm{NH}_{4}^{+}+\mathrm{OH}^{-}
$$

On the other hand, there are reports that the response value decreased again at higher humidity ( $60 \% \mathrm{RH}$ or higher), and this phenomenon was explained by the reduction of adsorption sites of $\mathrm{NH}_{3}$ by the competitive adsorption of $\mathrm{NH}_{3}$ and excess $\mathrm{H}_{2} \mathrm{O}[11,13,46,47]$.

In this study, the selectivity to other gases was not investigated. However, many papers have reported that PANI-based gas sensors had excellent selectivity toward $\mathrm{NH}_{3}$ gas and showed low responses to other volatile organic vapors and some common toxic gases $[18,38,40]$. Our sensors can be expected to possess this property of high selectivity, as the structure and the dopant of the PANI we used are not special.

To estimate the performance of the present PSt@PANI(4.5) sensor, the magnitudes of response of previously reported high-sensitivity $\mathrm{NH}_{3}$ gas sensors using PANI are summarized in Table 2. In this table, some response values were recalculated to match our definition $S=R_{\mathrm{g}} / R_{0}$. It should also be noted that many of the responses are values obtained 
in a humidified atmosphere. Therefore, there is a problem in that the detection performance of the sensors for $\mathrm{NH}_{3}$ gas alone cannot be compared. In general, such comparisons should be made on the assumption that the sensor responses obtained in a humidified atmosphere can be considered larger than those obtained in a dry atmosphere. Wojkiewicz et al. reported two systems of core-shell-type PANI sensor: one with a poly (vinylidene fluoride) (PVDF) core and the other with a poly (butyl acrylate) (PBuA) core [48]. A relatively porous film was formed with an average particle size of around 50-100 nm for PVDF@PANI, but adhesions between particles were observed. Regarding the PBuA@PANI, the nanoparticles deformed into two-axial ellipsoids and a film consisting of densely packed particles formed. Thus, considering that these sensor responses are measured under a humidified condition, these sensors did not provide a large sensor response compared to our PSt@PANI(4.5) sensor. Li et al. prepared hollow polyaniline nanospheres by coating sulfonated PSt cores with PANI and then extracting the PSt cores [38]. Interestingly, this resulted in a rambutan shape with a hollow sphere diameter of $250 \mathrm{~nm}$, which was one-tenth that of our microspheres, and a nanorod array length of $100 \mathrm{~nm}$. The authors stated that this characteristic shape had the effect of increasing the surface area and increasing the number of adsorption sites. Unfortunately, however, this rambutan-like nanosphere alone could not sufficiently increase the sensor response. High sensitivity was obtained by making it a hybrid with graphene oxide (GO). Since pure PANI had poor sensor performance, many reports utilize the synergistic effect of $\mathrm{p}$-type PANI and nano-structured n-type metal oxide semiconductors [45,49-51]. PANI-coated Au-loaded mesoporous $\operatorname{In}_{2} \mathrm{O}_{3}$ nanospheres showed a high response value ( $S=46$ at $100 \mathrm{ppm}$ in $50 \% \mathrm{RH}$ ) [45]. The $\mathrm{In}_{2} \mathrm{O}_{3} @ \mathrm{PANI}$ nanospheres ranged in diameter from $130 \mathrm{~nm}$ to $160 \mathrm{~nm}$, more than an order of magnitude smaller than our microspheres. A sensor that was particularly sensitive to low-concentration $\mathrm{NH}_{3}(S=9.8$ at $3 \mathrm{ppm}$ ) gas was obtained by growing PANI-CSA $/ \mathrm{TiO}_{2}$ on the inner wall of a glass tube [50]. More recently, the results of actually measuring the sensor response in an extremely low-concentration atmosphere of $1 \mathrm{ppm}$ or less have been reported. PANI-SrGe $\mathrm{O}_{4}$ nanocomposites had a unique hierarchical architecture with abundant mesopores [51]. The sensor showed an ultralow detection limit of $0.25 \mathrm{ppb}$ toward $\mathrm{NH}_{3}$ in $60 \% \mathrm{RH}$, although the sensor response was $S=3.1$ for $10 \mathrm{ppm} \mathrm{NH}_{3}$, which was small compared to that of the present PSt@PANI(4.5) sensor. Since there are some unclear points in the calculation of the detection limit, such as the inclusion of measurement error, a comparison of the reported LOD values should be done carefully. In addition, electrochemically synthesized PANI on commercial screen-printed three-electrode systems succeeded in detecting $32 \mathrm{ppb}$ in $70 \% \mathrm{RH}$, and the calculated LOD according to the formula from IUPAC recommendations was $23 \mathrm{ppb}$ [52]. Compared to the sensors reported above, our PANI microsphere sensor yielded greater sensitivity ( $S$ /Concentration) without utilizing the synergistic effect with metal oxide semiconductors or carbon nanomaterials and without using a special coating method or equipment.

Table 2. Comparison of PANI-based $\mathrm{NH}_{3}$ gas sensing performances of the present sensor with other previously reported sensors.

\begin{tabular}{|c|c|c|c|c|c|c|c|c|}
\hline Material & Features & Temp. $\left({ }^{\circ} \mathrm{C}\right)$ & Humidity (\% RH) & Conc. (ppm) & $S^{(1)}$ & S/Conc. (ppm $\left.{ }^{-1}\right)$ & LOD (ppb) & Ref. \\
\hline PSt@PANI(4.5) & Core-shell & 30 & dry & 100 & 77 & 0.77 & 46 & This work \\
\hline PSt@PANI(1.9) & Core-shell & 30 & dry & 250 & 37 & 0.15 & & This work \\
\hline PSt@PANI(1.9) & Core-shell & 30 & 50 & 250 & 62 & 0.25 & & This work \\
\hline PVDF@PANI & Core-shell & 25 & 50 & 10 & $2^{(2)}$ & 0.20 & 100 & [48] \\
\hline $\mathrm{In}_{2} \mathrm{O}_{3} @ \mathrm{PANI}$ & Core-shell & 20 & 50 & 100 & 46 & 0.46 & 500 & [45] \\
\hline GO/PANI & $\begin{array}{c}\text { Hollow } \\
\text { nanosphere }\end{array}$ & 20 & 25 & 100 & 32 & 0.32 & 50 & [38] \\
\hline $\mathrm{WO}_{3} @ \mathrm{PANI}$ & Nanoplate & 25 & 40 & 100 & 34 & 0.34 & & [49] \\
\hline $\mathrm{PANI} / \mathrm{TiO}_{2}$ & Tube & R.T. & dry & 100 & $17^{(2)}$ & 0.17 & & [50] \\
\hline $\mathrm{PANI} / \mathrm{Ti}_{3} \mathrm{C}_{2} \mathrm{~T}_{\mathrm{x}}$ & Flexible & 20 & dry & 50 & $4.0^{(2)}$ & 0.08 & 25 & [47] \\
\hline PANI/cellulose & Nanofiber & R.T. & 45 & 100 & 6.1 & 0.06 & 200 & [40] \\
\hline $\mathrm{PANI} / \mathrm{SrGe}_{4} \mathrm{O}_{9}$ & Nanocomposite & 25 & 60 & 10 & $3.1^{(2)}$ & 0.31 & 0.25 & [51] \\
\hline PANI on SPEs & $\begin{array}{l}\text { Electrochemically } \\
\text { deposited }\end{array}$ & 25 & 70 & 0.5 & 1.0 & 2.0 & 23 & [52] \\
\hline
\end{tabular}




\subsection{Mechanism of Response Increase}

We next discuss the reason why sensitivity was greatly improved by using the PANI microspheres. It is unlikely that the difference in the crystallinity of PANI due to the difference in the diameter of the microspheres affected the response value, as explained in Section 3.1.

Another possible reason for the improvement is that the size of the spherical particles affected the response value. It should be noted here that the electrodes were located below the sensing film. It can be theoretically calculated that the spheres occupy $74 \%$ of the volume when the spheres are closely packed, as illustrated in Figure 4a [53]. Therefore, as a general theory, film made of spherical particles has a large amount of space inside the film that is effective for gas diffusion to reaction sites near electrodes and is thus promising as a gas sensing film. However, when the sizes of spheres are irregular, as shown in Figure $4 \mathrm{~b}$, the small spheres fill the spaces between the large spheres, so that the packing efficiency becomes high [53]. In this regard, it can be said that producing spherical PANI particles having a uniform size was effective in increasing the sensor response. It is also important to explain why a larger response was obtained by simply increasing the size of the spheres. When PANI coats on the surface of nanometer-sized spheres, it is difficult to form a uniformly thin PANI shell layer on such tiny cores. As a result, PANI-coated particles have irregular shapes, and adhesions between nanospheres are likely to occur [48]. In fact, as can be seen in Figure 1, even in the case of microspheres, the smaller the particle size, the coarser the surface coating. Particle size miniaturization is generally effective at increasing total surface area but produces a trade-off effect in this case of increasing the packing efficiency (Figure 4c) and suppressing the diffusion of gas molecules to the reaction sites. Of course, when the microspheres are actually coated on the substrate, the arrangement of the spheres becomes more random, and the packing density is lower than in the case of dense packing (Figure $4 \mathrm{~d}$ ). To confirm the density of the PSt(x)@PANI films, cross sections of the sensors were observed with SEM and are shown in Figure 5. The drop-casting film formed a very dense structure in which irregularly shaped PANI nanoparticles of 100-200 nm were aggregated. On the other hand, the structure of the film consisting of PANI microspheres contained a lot of space inside. Moreover, microspheres with an average diameter of $4.5 \mu \mathrm{m}$ had more internal space due to the larger particle size, as expected. As a result, most of the PANI thin film present in the shell layer of the spheres was exposed to $\mathrm{NH}_{3}$ gas. Thus, it is considered that a large sensor response was obtained.

(a)

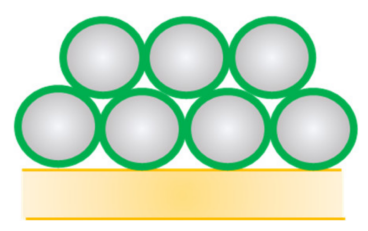

(b)

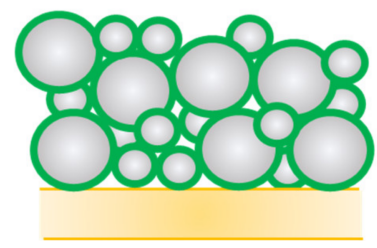

(c)

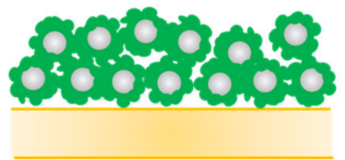

(d)

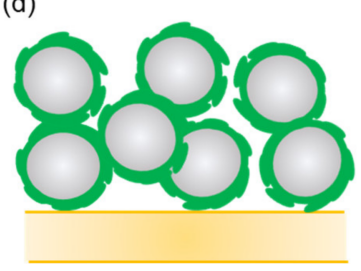

Figure 4. Cross-sectional illustration of core-shell-type PANI-sphere-deposited film: (a) close-packed structure consisting of uniform sized spheres, (b) structure consisting of irregularly sized spheres, (c) actual structure consisting of uniform nanometer-sized spheres, and (d) actual structure consisting of uniform micrometer-sized spheres.
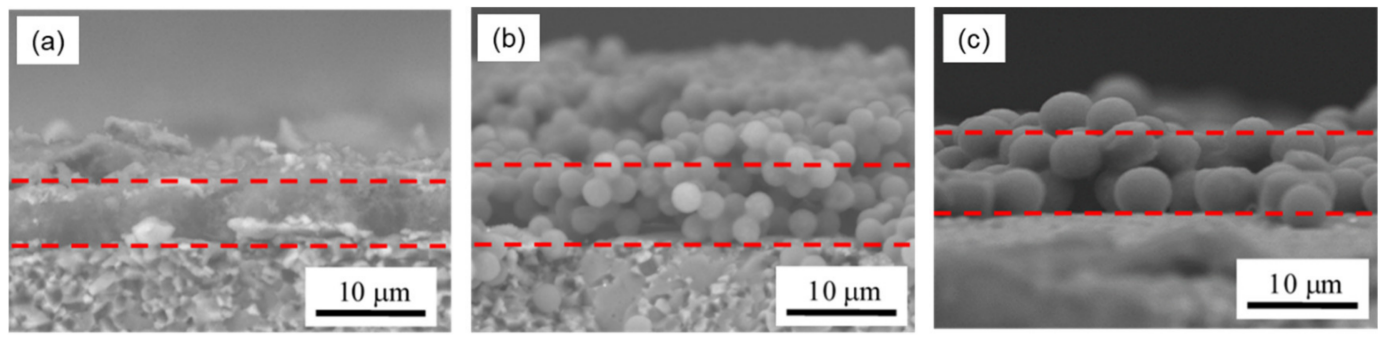

Figure 5. SEM images of cross sections of sensors: (a) deposited film, (b) PSt@PANI(2.5) film, and (c) PSt@PANI(4.5) film. 


\section{Conclusions}

$\mathrm{NH}_{3}$ gas sensors based on core-shell-type PANI microspheres were prepared. The present preparation method of PANI microspheres was very easy and did not require any special equipment. It was confirmed that the sensor response increased as the diameter of the microspheres increased. The present (PSt@PANI(4.5)) microsphere-based sensor showed higher sensitivity than the previously reported sensors based on typical structurecontrolled PANI and/or PANI composites toward $\mathrm{NH}_{3}$ gas at room temperature. This success in increasing the sensor response may have a very simple explanation: by producing a sensing film made of PANI uniformly coating micrometer-sized spheres, many spaces formed inside the film, resulting in the enhancement of the reaction between $\mathrm{NH}_{3}$ molecules and PANI. It is an important result of this study that our sensor achieved a greater sensor response with pure PANI by simply increasing the size of the core spheres. PSt@PANI microsphere sensors have advantages such as ease of preparation, low cost, and mass producibility. However, the response of this sensor was affected by humidity, as were the other PANI-based sensors, so it is necessary to take some measures against that effect. In the future, we intend to reduce the response time and increase the sensitivity by further optimizing the size of the spherical particles and by further reducing the thickness of the polyaniline shell.

Supplementary Materials: The following are available online at https:/ /www.mdpi.com/article/10 $.3390 / \mathrm{s} 21227522 / \mathrm{s} 1$, Figure S1: Illustration of an alumina substrate having a pair of interdigitated gold electrodes, Figure S2: Experimental setup used for $\mathrm{NH}_{3}$ gas sensing measurement, Figure S3: Sensing mechanism of PANI-based $\mathrm{NH}_{3}$ gas sensors.

Author Contributions: Conceptualization, methodology, and data curation, M.M.; validation, formal analysis and investigation, M.M., T.N., R.F. and S.S.; writing—original draft preparation, M.M.; writing-review and editing, M.M. and S.S. All authors have read and agreed to the published version of the manuscript.

Funding: This research received no external funding.

Institutional Review Board Statement: Not applicable.

Informed Consent Statement: Not applicable.

Data Availability Statement: Not applicable.

Acknowledgments: The structural observation was carried out on an FE-SEM and an XRD at the Research and Education Center of Materials Engineering, Course of Materials Design Engineering, Faculty of Engineering, Ehime University. We thank Masami Mori and Masaharu Fujioka at the Research and Education Center of Materials Engineering, Course of Materials Design Engineering, Faculty of Engineering, Ehime University, for their technical assistances.

Conflicts of Interest: The authors declare no conflict of interest.

\section{References}

1. Itoh, N.; Oshima, A.; Suga, E.; Sato, T. Kinetic enhancement of ammonia decomposition as a chemical hydrogen carrier in palladium membrane reactor. Catal. Today 2014, 236, 70-76. [CrossRef]

2. Hejze, T.; Besenhard, J.O.; Kordesch, K.; Cifrain, M.; Aronsson, R.R. Current status of combined systems using alkaline fuel cells and ammonia as a hydrogen carrier. J. Power Sources 2008, 176, 490-493. [CrossRef]

3. Nayak-Luke, R.; Banares-Alcantara, R.; Wilkinson, I. “Green” ammonia: Impact of renewable energy intermittency on plant sizing and levelized cost of ammonia. Ind. Eng. Chem. Res. 2018, 57, 14607-14616. [CrossRef]

4. Wang, L.; Xia, M.; Wang, H.; Huang, K.; Qian, C.; Maravelias, C.T.; Ozin, G.A. Greening ammonia toward the solar ammonia refinery. Joule 2018, 2, 1055-1074. [CrossRef]

5. Timmer, B.; Olthuis, W.; van den Berg, A. Ammonia sensors and their applications-A review. Sens. Actuators B 2005, 107, 666-677. [CrossRef]

6. Krishnan, S.T.; Devadhasan, J.P.; Kim, S. Recent analytical approaches to detect exhaled breath ammonia with special reference to renal patients. Anal. Bioanal. Chem. 2017, 409, 21-31. [CrossRef] [PubMed]

7. Natale, C.D.; Paolesse, R.; Martinelli, E.; Capuano, R. Solid-state gas sensors for breath analysis: A review. Anal. Chim. Acta 2014, 824, 1-17. [CrossRef] [PubMed] 
8. Righettoni, M.; Amann, A.; Pratsinis, S.E. Breath analysis by nanostructured metal oxides as chemo-resistive gas sensors. Mater. Today 2015, 18, 163-171. [CrossRef]

9. Stejskal, J.; Polyaniline, G.R.G. Preparation of a conducting polymer (IUPAC Technical Report). Pure Appl. Chem. 2002, 74, 857-867. [CrossRef]

10. Jiang, T.; Wan, P.; Ren, Z.; Yan, S. Anisotropic polyaniline/SWCNT composite films prepared by in situ electropolymerization on highly oriented polyethylene for high-efficiency ammonia sensor. ACS Appl. Mater. Interfaces 2019, 11, 38169-38176. [CrossRef]

11. Eising, M.; Cava, C.E.; Salvatierra, R.V.; Zarbin, A.J.G.; Roman, L.S. Doping effect on self-assembled films of polyaniline and carbon nanotube applied as ammonia gas sensor. Sens. Actuators B 2017, 245, 25-33. [CrossRef]

12. Gavgani, J.N.; Hasani, A.; Nouri, M.; Mahyari, M.; Salehi, A. Highly sensitive and flexible ammonia sensor based on S and N co-doped graphene quantum dots/polyaniline hybrid at room temperature. Sens. Actuators B 2016, 229, 239-248. [CrossRef]

13. Abdulla, S.; Mathew, T.L.; Pullithadathil, B. Highly sensitive, room temperature gas sensor based on polyaniline-multiwalled carbon nanotubes (PANI/MWCNTs) nanocomposite for trace-level ammonia detection. Sens. Actuators B 2015, 221, 1523-1534. [CrossRef]

14. Wu, Z.; Chen, X.; Zhu, S.; Zhou, Z.; Yao, Y.; Quan, W.; Liu, B. Enhanced sensitivity of ammonia sensor using graphene/polyaniline nanocomposite. Sens. Actuators B 2013, 178, 485-493. [CrossRef]

15. Liu, C.; Tai, H.; Zhang, P.; Yuan, Z.; Du, X.; Xie, G. A high-performance flexible gas sensor based on self-assembled PNI-CeO 2 nanocomposite thin film for trace-level $\mathrm{NH}_{3}$ detection at room temperature. Sens. Actuators B 2018, 261, 587-597. [CrossRef]

16. Tai, H.; Jiang, Y.; Xie, G.; Yu, J.; Chen, X. Fabrication and gas sensitivity of polyaniline-titanium dioxide nanocomposite thin film. Sens. Actuators B 2007, 125, 644-650. [CrossRef]

17. Bandgar, D.K.; Navale, S.T.; Mane, A.T.; Gupta, S.K.; Aswal, D.K.; Patil, V.B. Ammonia sensing properties of polyaniline/a-Fe ${ }_{2} \mathrm{O}_{3}$ hybrid nanocomposites. Synth. Met. 2015, 204, 1-9. [CrossRef]

18. Wang, X.; Meng, S.; Tebyetekerwa, M.; Weng, W.; Pionteck, J.; Sun, B.; Qin, Z.; Zhu, M. Nanostructured polyaniline/poly(styrenebutadiene-styrene) composite fiber for use as highly sensitive and flexible ammonia sensor. Synth. Met. 2017, 233, 86-93. [CrossRef]

19. Chen, S.; Sun, G. High Sensitivity Ammonia Sensor Using a Hierarchical Polyaniline/Poly(ethylene-co-glycidyl methacrylate) Nanofibrous Composite Membrane. ACS Appl. Mater. Interfaces 2013, 5, 6473-6477. [CrossRef] [PubMed]

20. Wang, Q.; Dong, X.; Pang, Z.; Du, Y.; Xia, X.; Wei, Q.; Huang, F. Ammonia Sensing Behaviors of TiO2-PANI/PA6 Composite Nanofibers. Sensors 2012, 12, 17046-17057. [CrossRef] [PubMed]

21. Merian, T.; Redon, N.; Zujobic, Z.; Stanisavljev, D.; Wojkiewicz, J.L.; Gizdavic-Nikolaidis, M. Ultra sensitive ammonia sensors based on microwave synthesized nanofibrillar polyanilines. Sens. Actuators B 2014, 203, 626-634. [CrossRef]

22. Khuspe, G.D.; Bandgar, D.K.; Sen, S.; Patil, V.B. Fussy nanofibrous network of polyaniline (PANi) for $\mathrm{NH}_{3}$ detection. Synth. Met. 2012, 162, 1822. [CrossRef]

23. Du, Z.; Li, C.; Li, L.; Yu, H.; Wang, Y.; Wang, T. Ammonia gas detection based on polyaniline nanofibers coated on interdigitated array electrodes. J. Mater. Sci. Mater. Electron. 2011, 22, 418-421. [CrossRef]

24. Chen, J.; Yang, J.; Yan, X.; Xue, Q. $\mathrm{NH}_{3}$ and $\mathrm{HCl}$ sensing characteristics of polyaniline nanofibers deposited on commercial ceramic substrates using interfacial polymerization. Synth. Met. 2010, 160, 2452-2458. [CrossRef]

25. Liu, M.-C.; Dai, C.-L.; Chan, C.-H.; Wu, C.-C. Manufacture of a Polyaniline Nanofiber Ammonia Sensor Integrated with a Readout Circuit Using the CMOS-MEMS Technique. Sensors 2009, 9, 869-880. [CrossRef] [PubMed]

26. Manigandan, S.; Jain, A.; Majumder, S.; Ganguly, S.; Kargupta, K. Formation of nanorods and nanoparticles of polyaniline using Langmuir Blodgett Technique: Performance study for ammonia sensor. Sens. Actuators B 2008, 133, 187-194. [CrossRef]

27. Li, Y.; Gong, J.; He, G.; Deng, Y. Synthesis of polyaniline nanotubes using $\mathrm{Mn}_{2} \mathrm{O}_{3}$ nanofibers as oxidant and their ammonia sensing properties. Synth. Met. 2011, 161, 56-61. [CrossRef]

28. Ngamna, O.; Morrin, A.; Killard, A.J.; Moulton, S.E.; Smyth, M.R.; Wallace, G.G. Inkjet printable polyaniline nanoformulations. Langmuir 2007, 23, 8569-8574. [CrossRef]

29. Liu, C.-F.; Maruyama, T.; Yamamoto, T. Conductive Blends of $p$-Conjugated Polymers and Thermoplastic Polymers in Late Form. Polym. J. 1993, 25, 363-372. [CrossRef]

30. Wiersma, A.E.; vd Steeg, L.M.A.; Jongeling, T.J.M. Waterborne core-shell despersions based on Intrinsically Conducting Polymers for Coating Aplications. Synth. Met. 1995, 71, 2269-2270. [CrossRef]

31. Lascelles, S.F.; Armes, S.P. Synthesis and characterization of micrometer-sized, polypyrrole-coated polystyrene latexes. J. Mater. Chem. 1977, 7, 1339-1347. [CrossRef]

32. Perruchot, C.; Chehimi, M.M.; Delamar, M.; Lascelles, S.F.; Armes, S.P. Surface characterization of polypyrrole-coated polystyrene latex by X-ray photoelectron spectroscopy. Langmuir 1996, 12, 3245-3251. [CrossRef]

33. Barthet, C.; Armes, S.P.; Lacelles, S.F.; Luk, S.Y.; Stanley, H.M.E. Synthesis and characterization of micrometer-sized, polyanilinecoated polystyrene latexes. Langmuir 1998, 14, 2032-2041. [CrossRef]

34. Paine, A.J.; Luymes, W.; McNulty, J. Despersion Polymerization of Styrene in Polar Solvents. 6. Influenece of Reaction Parameters on Particle Size and Molecular Weight in Poly(N-vinylpyrrolidone)-Stabilized Reactions. Macromolecules 1990, 23, 3104-3109. [CrossRef]

35. Paine, A.J. Dispersion Polymerization of Styrene in Polar Solvents. 7. A Simple Mechanistic Model to Predict Particle Size. Macromolecules 1990, 23, 3019-3117. [CrossRef] 
36. Abu, Y.M.; Aoki, K. Electrochemical properties of mono-particle-layer films of polyaniline-coated latex microspheres. J. Electroanal. Chem. 2004, 565, 219-225. [CrossRef]

37. Aoki, K.; Lei, T. Electrochemical event of single redox latex particles. Langmuir 2000, 16, 10069-10075. [CrossRef]

38. Li, S.; Wang, T.; Yang, Z.; He, J.; Wang, J.; Zhao, L.; Lu, H.; Tian, T.; Liu, F.; Sun, P.; et al. Room temperature high performance NH 3 sensor based on GO-rambutan-like polyaniline hollow nanosphere hybrid assembled to flexible PET substrate. Sens. Actuators $B$ 2018, 273, 726-734. [CrossRef]

39. Luzny, W.; Banka, E. Relations between the structure and electric conductivity of polyaniline protonated with camphorsulfonic acid. Macromolecules 2000, 33, 425-429. [CrossRef]

40. Yang, L.; Yang, L.; Wu, S.; Wei, F.; Hu, Y.; Xu, X.; Zhang, L. Three-dimensional conductive organic sulfonic acid co-doped bacterial cellulose/polyaniline nanocomposite films for detection of ammonia at room temperature. Sens. Actuators B 2020, 323, 128689. [CrossRef]

41. Xu, Z.; Gao, Y.; Liu, T.; Wang, L.; Bian, S.; Lin, J. General and facile method to fabricate uniform $\mathrm{Y}_{2} \mathrm{O}_{3}: \operatorname{Ln}^{3+}\left(\operatorname{Ln}^{3+}=\mathrm{Eu}^{3+}, \mathrm{Tb}^{3+}\right)$ hollow microspheres using polystyrene spheres as templates. J. Mater. Chem. 2012, 22, 21695-21703. [CrossRef]

42. Li, T.; Qin, Z.; Liang, B.; Tian, F.; Zhao, J.; Liu, N.; Zhu, M. Morphology-dependent capacitive properties of three nanostructured polyanilines through interfacial polymerization in various acidic media. Electrochim. Acta 2015, 177, 343-351. [CrossRef]

43. Erden, F.; Lai, S.C.; Chi, H.; Wang, F.; He, C. Tailoring the diameters of polyaniline nanofibers for sensor application. ACS Omega 2017, 2, 6506-6513. [CrossRef] [PubMed]

44. Zeng, F.-W.; Liu, X.-X.; Diamond, D.; Lau, K.T. Humidity sensors based on polyaniline nanofibers. Sens. Actuators B 2010, 143, 530-534. [CrossRef]

45. Li, S.; Diao, Y.; Yang, Z.; He, J.; Wang, J.; Liu, C.; Liu, F.; Lu, H.; Yan, X.; Sun, P.; et al. Enhanced room temperature gas sensor based on Au-loaded mesoporous $\operatorname{In}_{2} \mathrm{O}_{3}$ nanospheres@polyaniline core-shell nanohybrid assembled on flexible PET substrate for $\mathrm{NH}_{3}$ detection. Sens. Actuators B 2018, 276, 526-533. [CrossRef]

46. Wang, H.; Nie, S.; Li, H.; Ali, R.; Fu, J.; Xiong, H.; Li, J.; Wu, Z.; Lau, W.-M.; Mahmood, N.; et al. 3D hollow quasi-graphite capsules/polyaniline hybrid with a high performance for room-temperature ammonia gas sensors. ACS Sens. 2019, 4, 2343-2350. [CrossRef]

47. Li, X.; Xu, J.; Jian, Y.; He, Z.; Liu, B.; Xie, H.; Li, H.; Li, Z.; Wang, Y.; Tai, H. Toward agricultural ammonia volatilization monitoring: A flexible polyaniline/Ti3C2Tx hybrid sensitive films based gas sensor. Sens. Actuators B 2020, 316, 128144. [CrossRef]

48. Wojkiewicz, J.L.; Bliznyuk, V.N.; Carquigny, S.; Elkamchi, N.; Redon, N.; Lasri, T.; Pud, A.A.; Reynaud, S. Nanostructured polyaniline-based composites for ppb range ammonia sensing. Sens. Actuators B 2011, 160, 1394-1403. [CrossRef]

49. Fan, G.; Chen, D.; Li, T.; Yi, S.; Ji, H.; Wang, Y.; Zhang, Z.; Shao, G.; Fan, B.; Wang, H.; et al. Enhanced room-temperature ammonia-sensing properties of polyaniline-modified $\mathrm{WO}_{3}$ nanoplates derived via ultrasonic spray process. Sens. Actuators $B$ 2020, 312, 127892. [CrossRef]

50. Zhang, W.; Li, G.; Chen, Y.; Liu, S.; Xu, J.; Jing, C.; Zhang, J.; Yang, J.; Chen, Y.; Chu, J. Dynamic liquid phase deposition of doped nanostructured PANI tube sensor for trace-level $\mathrm{NH}_{3}$ gas detection. Sens. Actuators B 2020, 305, 127459. [CrossRef]

51. Zhang, Y.; Zhang, J.; Jiang, Y.; Duan, Z.; Liu, B.; Zhao, Q.; Wang, S.; Yuan, Z.; Tai, H. Ultrasensitive flexible $\mathrm{NH}_{3}$ gas sensor based on polyaniline $/ \mathrm{SrGeO}_{9}$ nanocomposite with ppt-level detection ability at room temperature. Sens. Actuators B 2020, $319,128293$. [CrossRef]

52. Korent, A.; Soderznik, K.Z.; Sturm, S.; Rozman, K.Z.; Redon, N.; Wojkiewicz, J.-L.; Duc, C. Facile fabrication of an ammonia-gas sensor using electrochemically synthesized polyaniline on commercial screen-printed three-electrode systems. Sensors 2021, 21, 169.

53. Yamada, S.; Kanno, J.; Miyauchi, M. Multi-sized sphere packing in containers: Optimization formula for obtaining the highest density with two different sized spheres. IPSJ Trans. Math. Modeling Appl. 2011, 4, 23-30. [CrossRef] 